\title{
Omurilik Yaralanmalı Hastalarda Lezyon Seviyesi ve Ciddiyeti ile Mesane Davranıșı Arasındaki İlișki
}

\author{
Relationship of Lesion Level and Severity with Bladder Behavior in Patients with Spinal Cord Injury
}

\author{
Necmettin YILDIZ, Hakan ALKAN, Nuray AKKAYA, Necdet ÇATALBAŞ, Füsun ARDIÇ \\ Pamukkale Üniversitesi Tıp Fakültesi, Fizik Tedavi ve Rehabilitasyon Anabilim Dalı, Denizli, Türkiye
}

Özet

Amaç: Omurilik yaralanmalı (OY) hastalarda lezyon seviyesi ve ciddiyeti ile ürodinamik bulgulara dayalı mesane davranışı arasındaki ilişkiyi araştırmak amaçlandı.

Gereç ve Yöntem: OY tanısı ile kliniğimizde yatarak rehabilitasyon programı uygulanan, spinal şok döneminden çıkmıș, 49 hasta çalışmaya dahil edildi. American Spinal Injury Association (ASIA) sınıflamasına göre, nörolojik lezyon seviyesi (servikal, torakal, lumbosakral) ve ciddiyeti (komplet, inkomplet) belirlendi. OY seviyesi ve ciddiyeti ile ürodinamik çalışma ile belirlenen nörojenik mesane tipi, maksimum sistometrik kapasite (MCC), kompliyans ve mesane boşaltım yöntemleri arasındaki ilişki değerlendirildi. Bulgular: Lezyon seviyesi ve ciddiyetine göre, OY'li hastalar arasında yaş, cinsiyet, hastalık süresi, nörojenik mesane tipi, MCC, kompliyans ve kabuldeki mesane boşaltım yöntemi açısından fark bulunmadı $(p>0,05)$. OY seviyesi ve ciddiyeti ile taburculukta mesane boşaltım yöntemi arasında anlamlı korelasyon saptandı (sırasıyla r: $0,33, p<0,01$ ve $r: 0,40, p<0,005$ ). Komplet yaralanmalı hastaların \%90,5'inin, inkomplet yaralanmalı hastaların \%3'ünün temiz aralıkı kateterizasyon (TAK) uyguladığı, inkomplet yaralanmalı hastaların \%32,1'inin spontan idrar yaptığı buna karşın komplet yaralanmalı hastalardan hiçbirinin spontan idrar yapmadığı belirlendi. Servikal yaralanmalı hastaların \%83,3'ünün, torakal yaralanmalı hastaların $\% 81,8^{\prime}$ inin ve lumbosakral yaralanmalı hastaların \%60'ının TAK uygulamakta olduğu saptandı. Lumbosakral lezyonlu olgularda spontan idrar yapma oranı (\%40), servikal ve torakal yaralanmalı hastalardan daha yüksek bulundu (sırasıyla $\% 8,3$ ve \%9,1). Aradaki farkın anlamlıı̆ı vaka sayısının az olması nedeniyle istatistiksel olarak test edilemedi. Taburculuk mesane boşaltım yöntemi ile OY seviyesi $(r: 0,33)$, OY ciddiyeti $(r: 0,40)$, MCC $(r: 0,33)$ ve kompliyans $(r: 0,34)$ arasında anlamlı korelasyon saptandı $(\mathrm{p}<0,05)$.

Sonuç: OY'li hastalarda taburculuk mesane boşaltım yöntemi ile; MCC, kompliyans, yaralanma seviyesi ve ciddiyeti ilişkili bulunurken, lezyon seviyesi ve ciddiyetinin mesane davranışını belirlemede yetersizliğ ürodinamik değerlendirmenin gerekliliğini ortaya koymaktadır.Türk Fiz Tıp Rehab Derg 2011;57:206-11.

Anahtar Kelimeler: Omurilik yaralanması, nörojenik mesane, mesane davranışı

\section{Summary}

Objective: It was aimed to investigate the relationship of lesion level and severity with bladder behavior based on urodynamic findings in patients with spinal cord injury (SCl).

Materials and Methods: Forty nine patients who were on inpatient rehabilitation programme in our clinic with the diagnosis of $\mathrm{SCl}$ after the spinal shock period were included in the study. Neurological level (cervical, thoracal, lumbosacral) and severity of the lesion (complete, incomplete) were set according to the American Spinal Injury Association (ASIA) classification. It was assessed if the level and severity of the $\mathrm{SCl}$ related to neurogenic bladder type, maximum cystometric capacity (MCC) and compliance which were designated with urodynamic study and methods of bladder management.

Results: There was no difference in terms of age, sex, disease duration, neurogenic bladder type, MCC, compliance, method of bladder management on admission according to the level and severity of the lesion among patients with $\mathrm{SCl}(p>0.05)$. Level and severity of $\mathrm{SCl}$ were significantly associated with the method of bladder drainage at discharge $(r: 0.33, p<0.01$ and $r: 0.40, p<0.005$, respectively). $90.5 \%$ of patients with complete $\mathrm{SCl}$ and $64.3 \%$ of patients with incomplete $\mathrm{SCl}$ were using clean intermittent catheterization $(\mathrm{CIC}), 32.1 \%$ of the patients with incomplete $\mathrm{SCl}$ urinated spontaneously, whereas none of the patients with complete $\mathrm{SCl}$ could urinate. It was found that $83.3 \%$ of cervical, $81.8 \%$ of thoracic and $60 \%$ of lumbosacral injured patients were using CIC. The greatest rate of spontaneous urination (40\%) was observed in people with lumbosacral injuries compared to cervical and thoracic levels (8.3 and 9.1\%, respectively).The significance of this difference could not be tested statistically due to the small sample size. Level ( $r: 0.33$ ) and severity ( $r: 0.40)$ of SCI, MCC (r: 0.33$)$ and compliance ( $r$ : 0.34 ) were all significantly correlated with the method of bladder management at discharge.

Conclusion: MCC, compliance, and level and severity of injury were found to be related with the method of bladder management at discharge in patients with $\mathrm{SCl}$. On the other hand, when the lesion level and severity are insufficient in determining the bladder behavior, the necessity of urodynamical evaluation arises. Turk J Phys Med Rehab 2011;57:206-11.

Key Words: Spinal cord injury, neurogenic bladder, bladder behavior 


\section{Giriş}

Omurilik yaralanması (OY) sonrası gözlenen nörojenik mesane fonksiyon bozukluğu, yalnızca üst üriner sistem fonksiyonlarını değil hastaların yaşam kalitesini de etkilemektedir (1). Bu nedenle mesane davranışının doğru bir şekilde değerlendirilmesi OY'li hastalar için önemlidir. Klasik olarak, komplet suprasakral lezyonlarda over-aktif detrüsör (OD) bulguları görülürken, sakral ve infrasakral lezyonlarda akontraktil detrüsör (AD) bulguları ve artmış mesane kompliyansı görülür $(2,3)$. Ancak, bazı yazarlar nörolojik ve ürodinamik bulguların her zaman tam korelasyon göstermeyebileceğini bildirmişlerdir (4-7). Çalışmalarda, OY seviyesi ve ciddiyeti ile mesane davranışı arasındaki ilişki üzerinde durulmakta fakat mevcut çalışmaları, farklı değerlendirmelerin kullanılması nedeniyle karşılaştırmak zor olmaktadır (2-4,6-9).

Bu çalışmada, OY'li hastalarda yaralanma seviyesi ve ciddiyeti ile ürodinamik bulgulara dayalı mesane davranışı arasındaki ilişkinin ortaya konulması amaçlanmıştır.

\section{Gereç ve Yöntem}

OY tanısı ile kliniğimizde yatarak rehabilitasyon programı uygulanan ve ürodinamik değerlendirmesi yapılan 49 hasta retrospektif olarak çalışmaya alınmıştır. Hastaların yaş, cinsiyet, eğitim düzeyi, OY nedeni, yatışa kabul edilene dek geçen süreleri (başvuru süresi) sorgulanmış, yatış süreleri ve hastalık süreleri hesaplanmış ve sistem muayeneleri yapılmıştır. Nörolojik lezyon seviyesi ve ciddiyeti American Spinal Injury Association (ASIA) sınıflamasına göre belirlenmiştir (10). Hastalar, nörolojik lezyon seviyesine göre; servikal, torakal ve lumbosakral (LS) ve lezyonun ciddiyetine göre komplet ve inkomplet şeklinde gruplara ayrılarak değerlendirilmiştir.

Antikolinerjik tedavi alan dört hastada, ürodinamik değerlendirmeden bir hafta önce tedaviye ara verilmiştir. Değerlendirme öncesi tam idrar ve idrar kültürü sonuçları değerlendirilip, enfekte olan hastalar uygun antibiyotik tedavisinden sonra çalışmaya alınmıştır. Ayrıca ultrasonografi ile tüm üriner sistem incelenmiştir. Ürodinamik değerlendirme "Medical Measurement Systems" (MMS) marka ürodinami cihazı ve 8 French çift lümenli steril üretral kateter ile yapılmıştır. Mesanedeki idrar boşaltıldıktan sonra, oda sıcaklığında serum fizyolojik ile $20 \mathrm{ml} /$ dakika doldurma hızında mesane doldurulmuştur. Ürodinamik çalışmada, anal sfinkter EMG aktivitesi, karın içi basıncı (Pabd) ve detrüsör basıncı (Pdet) tespit edilmiştir. Pdet, mesane içi basıncından (Pves) Pabd çıkarılarak hesaplanmıştır. Maksimum sistometrik kapasite (MCC), belirgin işeme ya da kaçak gelişen, belirgin rahatsızlık oluşan veya intravezikal basıncın $40 \mathrm{cmH}_{2} \mathrm{O}^{\prime}$ yu aştığı hacim olarak tanımlanmıştır (11). Kompliyans, International Continans Society'nin (ICS) tanımına göre hesaplanmıştır (12). Buna göre, iki standart noktanın kullanılması önerilmektedir. İlki; mesane doluşu başladığındaki detrüsör basıncı ve buna karşı gelen mesane volümü, ikincisi; sistometrik kapasitedeki ya da idrar kaçırmaya yol açan herhangi bir detrüsör kontraksiyonunun başlamasından hemen önceki detrüsör basıncı ve buna karşı gelen mesane volümüdür. Ürodinamik bulgulara göre belirlenen nörojenik mesane tipi; $O D$ ve $A D$ olmak üzere iki grupta (2) ve mesane boşaltma yöntemi; daimi kateter, temiz aralıklı kateterizasyon (TAK), spontan ve bez/kondom kateter olmak üzere dört grupta değerlendirilmiştir. Uygulanacak mesane boşaltma yöntemini belirlerken hasta tercihi ve TAK işleminin hasta veya hastaya bakım veren kişi tarafından uygulanabilirliği göz önüne alınmıştır. Spontan idrar yapabilen hastalarda, spontan idrar yapmaya geçme kriterleri; hastanın istenilen zamanda ve yerde işeme başlatabilmesi, işeme sonrası kabul edilebilir oranda rezidü idrar kalması (en fazla, işenen idrar/rezidü idrar $=1 / 5$ olacak miktarda) ve işeme esnasında detrüsör basıncı erkeklerde $80 \mathrm{~cm} \mathrm{H} \mathrm{O}^{\prime}$ nun, kadınlarda $60 \mathrm{~cm}$ $\mathrm{H}_{2} \mathrm{O}^{\prime}$ nun altında olması olarak belirlenmiştir (13).

OY'li hastalarda, yukarıdaki kriterlere göre belirlenen ürodinamik parametreler (nörojenik mesane tipi, MCC ve kompliyans) ve mesane boşaltım yöntemleri ile OY seviyesi ve ciddiyeti arasındaki ilişki değerlendirilmiştir.

İstatistiksel çalışmalar "SPSS for Windows 11.0" paket programı kullanılarak yapılmıştır. Çalışmamızda, sürekli değişkenleri karşılaştırmak amacıyla değişkenlerin normal dağılıma uygunluğu test edildikten sonra parametrik olmayan analizler yapılmıştır. Sürekli değişkenlerin ortalamaları arasındaki farkın analizi için Mann-Whitney $U$ ve Kruskall Wallis testi, niteliksel değişkenlerin karşılaştırılmasında ki-kare testi ve korelasyon analizleri için Spearman testi kullanılmıştır. İstatistiksel anlamlılık düzeyi olarak $\mathrm{p}<0.05$ kabul edilmiştir.

\section{Bulgular}

Hastalarımızın yaş ortalaması $47,00 \pm 17,28$ yıl olup, 34 'ü $(\% 69,4)$ erkek, $15^{\prime} i(\% 30,6)$ kadın idi. Başvuru süresi ortalama $116,79 \pm 128,85$, hastalık süresi $170,06 \pm 126,08$ gündü. Hastaların çoğunun eğitim düzeyi ilköğretim $(\% 77,6)$ olup, yaralanma nedenleri arasında trafik kazası $(\% 32,7)$ birinci sıradaydı. Çoğunluğu torakal $(\% 44,9)$ ve inkomplet $(\% 57,1)$ yaralanmalı hastalar oluşturmakta idi. Nörojenik mesane tipi, $26(\% 53,1)$ hastada OD, 23 (\%46,9) hastada AD olarak belirlenmişti (Tablo 1).

Hastaneye kabulde mesane boşaltım yöntemi olarak hastaların \%71,4'ü daimi kateter, \%16,3'ü TAK uygularken, taburculukta TAK uygulayan hastaların oranının $\% 75,5^{\prime}$ e yükseldiği, spontan işemenin \%18,4 hastada sağlandığı ve daimi kateter kullanımının $\% 6,1^{\prime}$ e düştüğü gözlendi (Tablo 1). TAK, hastaların \%67,6'sında $(25 / 37)$ hastanın kendisi, \%32,4'ünde $(12 / 37)$ ise hastaya bakım veren kişi tarafından uygulanmaktaydı.

\section{OY Ciddiyeti}

Komplet yaralanmalı 21 hastanın 14'ünde (\%66,7) OD, 7'sinde $(\% 33,3)$ AD saptanmıştır. İkomplet yaralanmalı 28 hastanın ise 12 'sinde $(\% 42,9)$ OD, 16 'sında $(\% 57,1)$ AD saptanmıştır. Komplet yaralanmalı hastalarda, MCC $(377,38 \pm 145,44)$ ve kompliyans $(20,56 \pm 18,13)$, inkomplet yaralanmalı hastalardan (sırasıyla $423,21 \pm 126,66$ ve $30,26 \pm 21,89$ ) daha düşük bulunmuştur. Buna karşın, komplet ve inkomplet yaralanmalı hastalar arasında; yaş, cinsiyet, hastalık süresi, nörojenik mesane tipi, MCC ve kompliyans açısından istatistiksel anlamlı fark bulunmamıştır $(p>0,05)$ (Tablo 2).

OY ciddiyeti ile taburculukta mesane boşaltım yöntemi arasında anlamlı korelasyon saptanmıştır ( $r: 0,40, p<0,005)$ (Tablo 3). Komplet yaralanmalı hastaların $\% 90,5^{\prime} \mathrm{i}$ taburculukta mesane boşaltım yöntemi olarak TAK uygulamakta iken, inkomplet yaralanmalı hastaların \%64,3'ünün TAK ile, \%32,1'inin spontan olarak idrar yaptığı belirlenmiştir. Buna karşın komplet yaralanmalı hastalardan hiçbiri spontan idrar yapmamaktadır. Aradaki farkın anlamlılığı vaka sayısının az olması nedeniyle test edilememiştir (Tablo 2). 


\section{OY Seviyesi}

Servikal yaralanmalı 12 hastanın 9'unda (\%75) OD, 3'ünde (\%25) AD, torakal yaralanmalı 22 hastanın 12'sinde $(\% 54,6) \mathrm{OD}$, 10 'unda $(\% 45,4)$ AD ve LS yaralanmalı 15 hastanın 9'unda $(\% 60)$ OD, 6'sında (\%40) AD saptanmıştır. Lezyon seviyelerine göre yaş,

Tablo 1. Omurilik yaralanmalı hastaların $(n=49)$ klinik özellikleri.

\begin{tabular}{|c|c|c|}
\hline & & (\%) \\
\hline \multirow[t]{2}{*}{ Cinsiyet } & Erkek & $34 \quad(69,4)$ \\
\hline & Kadın & $15 \quad(30,6)$ \\
\hline Yaş & (yll) (Orttss) & $47,00 \pm 17,28$ \\
\hline Başvuru süresi & (gün) (Ortt\$SS) & $116,79 \pm 128,85$ \\
\hline Yatış süresi & (gün) (OrttSS) & $52,65 \pm 35,26$ \\
\hline Hastalık süresi & (gün) (Ort+SS) & $170,06 \pm 126,08$ \\
\hline \multirow[t]{4}{*}{ Eğitim Düzeyi } & Okur yazar değil & $1 \quad(2,0)$ \\
\hline & İlköğretim & $38 \quad(77,6)$ \\
\hline & Lise & $8 \quad(16,3)$ \\
\hline & Üniversite & $2 \quad(4,1)$ \\
\hline \multirow[t]{6}{*}{ OY nedeni } & Trafik kazası & $16 \quad(32,7)$ \\
\hline & Yüksekten düşme & $15 \quad(30,6)$ \\
\hline & Ameliyat sonrası & $9 \quad(18,4)$ \\
\hline & Ateşli silah yaralanması & $4 \quad(8,2)$ \\
\hline & Göçük altında kalma & $(6,1)$ \\
\hline & Enfeksiyon & $1 \quad(2,0)$ \\
\hline \multirow[t]{3}{*}{ OY seviyesi } & Servikal & $12(24,5)$ \\
\hline & Torakal & $22 \quad(44,9)$ \\
\hline & Lumbosakral & $15 \quad(30,6)$ \\
\hline \multirow[t]{2}{*}{ OY ciddiyeti } & Komplet (ASIA A) & $21 \quad 42,9)$ \\
\hline & İnkomplet (ASIA B-D) & $28 \quad(57,1)$ \\
\hline \multicolumn{3}{|c|}{ Kabulde mesane boşaltım yöntemi } \\
\hline & Daimi kateter & $35 \quad(71,4)$ \\
\hline & TAK & $8 \quad(16,3)$ \\
\hline & Spontan & $4 \quad(8,2)$ \\
\hline & Bez/Kondom kateter & $(4,1)$ \\
\hline \multicolumn{3}{|c|}{ Nörojenik mesane tipi } \\
\hline & OD & $26 \quad(53,1)$ \\
\hline & $A D$ & $23 \quad(46,9)$ \\
\hline \multicolumn{2}{|c|}{ Maksimum sistometrik kapasite (ml) (Ort+SS) } & $403,57 \pm 135,51$ \\
\hline \multicolumn{2}{|c|}{ Kompliyans $\left(\mathrm{ml} / \mathrm{cmH}_{2} \mathrm{O}\right) \quad(\mathrm{Ort} \pm \mathrm{SS})$} & $26,10 \pm 20,74$ \\
\hline \multicolumn{3}{|c|}{ Taburculuk mesane boşaltım yöntemi } \\
\hline & Daimi kateter & $(6,1)$ \\
\hline & TAK & $37 \quad(75,5)$ \\
\hline & Spontan & $9 \quad(18,4)$ \\
\hline
\end{tabular}

OY: Omurilik yaralanması, ASIA: American Spinal Injury Association TAK: Temiz aralıklı kateterizasyon

OD: Over-aktif detrüsör, AD: Akontraktil detrüsör cinsiyet, hastalık süresi, nörojenik mesane tipi, MCC ve kompliyans açısından istatistiksel olarak anlamlı fark bulunmamıştır $(p>0.05)$ (Tablo 4).

OY seviyesi ile taburculukta mesane boşaltım yöntemi arasında anlamlı korelasyon olduğu belirlenmiştir ( $r: 0,33, p<0,01)$ (Tablo 3). Taburculukta mesane boşaltım yöntemi olarak servikal yaralanmalı hastaların \%83,3'ünün, torakal yaralanmalı hastaların \%81,8'inin ve LS yaralanmalı hastaların \%60'ının TAK uygulamakta olduğu saptanmıştır. LS lezyonlu olgularda spontan idrar yapma oranı (\%40), servikal ve torakal yaralanmalı hastalardan daha yüksek bulunmuştur (sırasıyla \%8,3 ve \%9,1). Aradaki farkın anlamlılı̆̆ vaka sayısının az olması nedeniyle test edilememiştir (Tablo 4).

\section{Nörojenik Mesane Tipi}

Nörojenik mesane tipi ile MCC $(r: 0,46, p<0,005)$ ve kompliyans $(r: 0,69, p<0,001)$ arasında korelasyon saptanmıştır (Tablo 3). MCC'nin, mesane tipi OD olan hastalarda ortalama $345,00 \pm 138,30 \mathrm{ml}$ olduğu ve $A D$ olan hastalara göre $(469,78 \pm 98,44)$ istatistiksel olarak anlamlı düzeyde düşük olduğu saptanmıştır $(p<0,05)$. Benzer şekilde, kompliyansın da mesane tipi OD olan hastalarda $12,88 \pm 6,81 \mathrm{ml} / \mathrm{cmH}_{2} \mathrm{O}$ olduğu ve $\mathrm{AD}$ olan hastalara $(41,05 \pm 21,10)$ göre istatistiksel olarak anlamlı düzeyde düşük olduğu görülmüştür $(p<0,05)$. Hastaların mesane tipine göre taburculuk mesane boşaltım yöntemi dağılımlarının birbirine yakın olduğu görülmüştür (Tablo 5).

Taburculuk mesane boşaltım yöntemi ile OY seviyesi ( $r: 0,33$, $p<0,01)$, OY ciddiyeti $(r: 0,40, p<0,005), \operatorname{MCC}(r: 0,33, p<0,01)$ ve kompliyans $(r: 0,34, p<0,01)$ arasında anlamlı korelasyon saptanmıştır. Ayrıca, MCC ile kompliyans ( $r: 0,76, p<0,001)$ arasında pozitif korelasyon olduğu da belirlenmiştir (Tablo 3 ).

\section{Tartışma}

Sonuçlarımıza göre; OY'li hastalarda, OY seviyesi ve ciddiyetine bağlı olarak nörojenik mesane tipi, MCC ve kompliyansın anlamlı düzeyde değişmediği, ancak hem OY seviyesinin hem de OY ciddiyetinin taburculuk mesane boşaltım yöntemi ile ilişkili olduğu gözlenmiştir. Taburculukta, spontan idrar yapma oranlarının inkomplet yaralanmalı hastalarda, komplet yaralanmalı hastalardan ve LS lezyonlu hastalarda, torakal ve servikal lezyonlu hastalardan yüksek olduğu ortaya konulmuştur. Taburculuk mesane boşaltım yöntemi ile ilişkili olduğu belirlenen diğer iki faktörün, MCC ve mesane kompliyansı olduğu belirlenmiştir.

Spinal şok döneminden sonra komplet suprasakral yaralanmalarda beklenen sonuç, OD'dir. Komplet sakral yaralanmalarda ise $A D$ görülür ve mesane kompliyansı $\operatorname{artar}(2,3)$. Lezyon seviyesi ile mesane davranışını ilişkilendiren çalışmaların $(2,3,14)$ aksine bazı çalışmalarda, ürodinamik incelemeler ile ortaya konan nörojenik mesane fonksiyon bozukluklarının, lezyon seviyesi ile her zaman uyumlu olmayabileceği bildirilmektedir $(4,9,15,16)$. Bu sonucu destekler şekilde; çalışmamızda, lezyon seviyesi ile nörojenik mesane tipi, MCC ve mesane kompliyansı arasında anlamlı ilişki olmadığı ortaya konulmuştur. Ayrıca çalışmalarda komplet lezyonlu hastalarda lezyon seviyesi ile mesane davranışı arasında güçlü bir korelasyon olduğu, inkomplet hastalarda bu korelasyonun zayıf olduğu bildirilmektedir (5). Çalışmamızda, lezyon seviyesinin mesane davranışları üzerine etkisi değerlendirilirken, alt grup olarak lezyon ciddiyeti (komplet/inkomplet) açısından değerlendirilememiş olması sonuçlarımızı karşılaştırırken göz önünde bulundurulmalıdır. 
Suprasakral yaralanmalı hastaların çoğunluğunda OD bulunmaktadır. Ancak yapılan bir çalışmada, bunun tek seviyeli OY'li hastalar için geçerli olabileceği, çok seviyeli OY'li hastalarda yaralanma seviyesi ile nörojenik mesane tipinin birliktelik göstermediği bildirilmiştir (2). OY'li hastalardaki somatik nörolojik bulgular ve ürodinamik sonuçlar arasındaki korelasyon genellikle doğru olmakla birlikte kesin değildir (7). Sacomani ve ark. (17) tarafından yapılan bir çalışmada servikal ve torakal yaralanmalı hastaların çoğunun OD tip mesaneye sahip olduğu fakat servikal yaralanmalı hastaların $\% 4,5^{\prime}$ inde ve torakal yaralanmalı hastaların \%23,1'inde AD mevcut olduğu ortaya konulmuştur. Çalışmamızda ise bu oranların daha yüksek (servikalde \%25, torakalde \%45,4) olduğu gözlenmektedir. Bu sonuçlara açıklama getirmede birkaç faktör göz önüne alınmalıdır. Öncelikle bir lezyonun komplet ya da inkomplet olup olmadığı bazen bir tanımlama konusudur, somatik olarak bilinen bir komplet lezyon otonomik olarak inkomplet lezyona dönüşmeyebilir veya tersi de doğru olabilir. Ayrıca, somatik olarak değerlendirme tek seviyede yaralanmayı gösterse bile aslında yaralanma farklı düzeylerde çok seviyeli olabilir $(6,7)$.

Literatür taramamızda, OY seviyesi ile taburculuk mesane boşaltım yönteminin ilişkisini değerlendiren bir çalışmaya rastlanılmamıştır. Çalışmamızda ise, LS lezyonlu hastalarda spontan idrar yapma oranının torakal ve servikal lezyonlu hastalardan daha yüksek olduğu gözlenmiştir. Bradley ve ark'na (18) göre, $O D$ veya $A D$ olduğu halde normal işemenin olması mesane ve dış sfinkterin istemli olarak kontrol edilebilmesine bağlıdır. Aynı zamanda istemli sfinkter aktivitesinin sensorimotor korteks ve pudental nükleus arasındaki bağlantılarla ve işeme kontrolünün kortikal (frontal korteks), subkortikal bölgeler ve beyindeki diğer bölgelerin (mezensefalik-pontin-medullar retiküler formasyon) uyum içinde çalışması ile ilgili olduğunu belirtmişlerdir.

ASIA sınıflaması somatik sinir sisteminin değerlendirildiği klinik bir skala olup, bu sınıflamada otonom sinir sisteminin (OSS) fonksiyon durumu dikkate alınmamaktadır (10). Alt üriner sistemin OSS innervasyonu ürodinamik inceleme ve elektrofizyolojik testler ile değerlendirilebilir (19). Çalışmamızda, alt üriner sistem fonksiyon bozukluğunun (OSS disfonksiyonu) belirlenmesinde yaralanmanın komplet ya da inkomplet olmasının, bir başka ifade ile duysal ve/veya motor korunmanın etkisinin değerlendirmesi de yapılmıştır. Sonuçlarımız; OY'nin komplet ya da inkomplet oluşunun, nörojenik mesane tipi, MCC ve mesane kompliyansı üzerinde etkisi olmadığını göstermektedir. Ancak OY ciddiyetinin taburculuk mesane boşaltım yöntemi ile orta derecede korele olduğu belirlenmiştir. Spontan idrar yapma oranı, inkomplet yaralanmalı hastalarda, komplet yaralanmalı hastalardan daha yüksek bulunmuştur. Moslavac ve ark'nın (20) OD fonksiyonuna sahip OY'li hastalarda yaptıkları çalışmada, komplet ve inkomplet yaralanmalı hastaların MCC'leri arasında fark saptanmamıştır. Rapidi ve ark'nın (8) çalışmasında, komplet ve inkomplet yaralanmalı hastalar arasında nörojenik mesane tipi, mesane boşaltma yöntemi ve kompliyans açısından fark olmadığı ifade edilmiştir. Weld ve ark'nın (2) çalışmasında da yaralanmanın komplet olup olmamasının nörojenik mesane tipini etkilemediği bildirilmiştir. Bu çalışmaların sonuçları sonuçlarımızın çoğu ile uyumlu olmakla birlikte, çalışmamızda mesane boşaltım yöntemi olarak iki grup arasında farklılıklar saptanmıştır. Taburculukta, inkomplet grupta toplam TAK ve spontan mesane boşaltımı oranı $\% 96,4$ olup daimi kateter kullanımı \%3,6'lık düşük bir oranda

Tablo 2. Omurilik yaralanmasının ciddiyeti ile ilişkili faktörler.

\begin{tabular}{|c|c|c|c|}
\hline $\mathrm{n}=49$ & Komplet $n=21$ & Inkomplet $\mathrm{n}=\mathbf{2 8}$ & p \\
\hline Yaş (yll) (Ortt+SS) & $41,90 \pm 13,52$ & $50,82 \pm 18,98$ & 0,077 \\
\hline Cinsiyet, n (\%) & $15(71,4)$ & $19(67,9)$ & \multirow{2}{*}{0,520} \\
\hline Kadın & $6(28,6)$ & $9(32,1)$ & \\
\hline 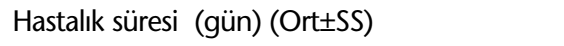 & $175,61 \pm 99,43$ & $165,89 \pm 144,55$ & 0,210 \\
\hline \multicolumn{4}{|l|}{ Kabulde mesane boşaltım yöntemi, n (\%) } \\
\hline Daimi kateter & $17(81,0)$ & $18(64,3)$ & \multirow{4}{*}{$\mathrm{TE}$} \\
\hline TAK & $4(19,0)$ & $4(14,3)$ & \\
\hline Spontan & - & $4(14,3)$ & \\
\hline Bez & - & $2(7,1)$ & \\
\hline \multicolumn{4}{|l|}{ Nörojenik mesane tipi, n (\%) } \\
\hline OD & $14(66,7)$ & $12(42,9)$ & \multirow{2}{*}{0,101} \\
\hline$A D$ & $7(33,3)$ & $16(57,1)$ & \\
\hline Maksimum sistometrik kapasite $(\mathrm{ml})(\mathrm{Ort} \pm \mathrm{SS})$ & $377,38 \pm 145,44$ & $423,21 \pm 126,66$ & 0,350 \\
\hline Kompliyans $\left(\mathrm{ml} / \mathrm{cmH}_{2} \mathrm{O}\right) \quad(\mathrm{Ort} \pm \mathrm{SS})$ & $20,56 \pm 18,13$ & $30,26 \pm 21,89$ & 0,138 \\
\hline \multicolumn{4}{|l|}{ Taburculuk mesane boşaltım yöntemi, n (\%) } \\
\hline Daimi kateter & $2(9,5)$ & $1(3,6)$ & \multirow{3}{*}{ TE } \\
\hline TAK & $19(90,5)$ & $18(64,3)$ & \\
\hline Spontan & - & $9 \quad(32,1)$ & \\
\hline
\end{tabular}


kalmıştır. Komplet grupta ise spontan işeme sağlanamamış daimi kateter oranı \%9,5 olmuştur. Schurch ve ark'nın (21) torakolomber yaralanmalı post-travmatik paraplejik 55 hasta üzerinde yaptıkları çalışmada, sakral duyunun korunmadığı (komplet) vakalarda mesane iyileşmesinin kötü olduğu bildirilmiş olup, bu sonuç; çalışmamızda saptanan komplet yaralanmalı hastalarda düşük spontan idrar boşaltma oranlarını desteklemektedir.

Tablo 3. Mesane özellikleri ile korelasyon gösteren faktörler.

\begin{tabular}{|l|c|c|c|c|}
\hline & $\begin{array}{c}\text { OY } \\
\text { Seviyesi }\end{array}$ & $\begin{array}{c}\text { OY } \\
\text { Ciddiyeti }\end{array}$ & MCC & Kompliyans \\
\hline $\begin{array}{l}\text { Nörojenik } \\
\text { Mesane Tipi, } r=\end{array}$ & 0,252 & 0,236 & $0,461^{* *}$ & $0,688^{* *}$ \\
\hline $\begin{array}{l}\text { Taburculuk mesane } \\
\text { boşaltım yöntemi, } r=\end{array}$ & $0,333^{*}$ & $0,400^{* *}$ & $0,330^{*}$ & $0,337^{*}$ \\
\hline Kompliyans, $r=$ & 0,211 & 0,214 & $0,765^{* * *}$ & - \\
\hline
\end{tabular}

${ }^{*} \mathrm{P}<0.01,{ }^{* *} \mathrm{P}<0.005,{ }^{* * *} \mathrm{P}<0.001$

OY: Omurilik yaralanması, MCC: Maksimum sistometrik kapasite
Araştırmaların çoğu, nörojenik mesanenin teşhis ve tedavisinde ürodinamik çalışmaların şart olduğunu ve bu çalışmalarla elde edilen sonuçlara göre mesane tipine karar vermenin daha doğru olacağını göstermektedir $(3,5,9,14,21-24)$. Çalışmamızda, beklenenin dışında saptanan ürodinamik bulguların olası patofizyolojisi içerisinde, lezyon distalinde oluşan dejenerasyon veya reorganizasyon, desentralizasyon, subklinik lumbosakral lezyonun olması, detrusör kontraksiyonunun somatik refleks aktiviteden daha geç dönmesi (suprasakral $A D^{\prime}$ de), mesane ve somatik yapılar arasındaki ilişkinin bozulması yer almaktadır (9). Ayrıca suprasakral lezyonlarda AD varlığında artefakt oluşturabilecek iki durum unutulmamalıdır. Ya ürodinami sırasında refleks detrüsör kontraksiyonunu oluşturacak kadar mesane doldurulmamıştır ya da mesanenin aşırı distansiyonuna bağlı detrüsör kasılamamaktadır (25). Bu iki durumun olmaması için çalışma dizaynında dikkatli davranılmıştır.

Çalışmamızda OD fonksiyonu olan nörojenik mesaneye sahip hastalarda, AD fonksiyonuna sahip olanlara göre MCC ve mesane kompliyansının daha düşük olduğu belirlenmiştir. Literatürde, $O Y^{\prime} l i$ hastalarda nörojenik mesane tipi ile ilişkili faktörlerin değerlendirildiği çalışma sayısı az olup, veriler sonuçlarımız ile uyumludur (26). Ayrıca, çalışmamızda MCC ile kompliyans

Tablo 4. Omurilik yaralanmasının seviyesi ile ilişkili faktörler.

\begin{tabular}{|c|c|c|c|c|}
\hline$n=49$ & Servikal $(S) n=12$ & Torakal $(T) n=22$ & Lumbo-sakral (LS) $\mathrm{n}=15$ & $\mathbf{P}$ \\
\hline Yaş (yll) (OrttSS) & $45,16 \pm 17,28$ & $44,77 \pm 14,65$ & $51,73 \pm 20,81$ & 0,352 \\
\hline Cinsiyet, n (\%) & $8(66,7)$ & $17(77,3)$ & $9(60,0)$ & \\
\hline Kadın & $4(33,3)$ & $5(22,7)$ & $6(30,0)$ & 0,522 \\
\hline Hastalık süresi (gün) (Ort+SS) & $167,08 \pm 146,33$ & $189,95 \pm 142,05$ & $143.26 \pm 77.54$ & 0,627 \\
\hline \multicolumn{5}{|l|}{ Kabulde mesane boşaltım yöntemi, n (\%) } \\
\hline Daimi kateter & $11(91,7)$ & $13(59,1)$ & $11(73,3)$ & \multirow{4}{*}{ TE } \\
\hline TAK & - & $7(31,8)$ & $1(6,7)$ & \\
\hline Spontan & $1(8,3)$ & $1(4,5)$ & $2(13,3)$ & \\
\hline Bez & - & $1(4,5)$ & $1(6,7)$ & \\
\hline \multicolumn{5}{|l|}{ Nörojenik mesane tipi, n (\%) } \\
\hline OD & $9(75,0)$ & $12(54,6)$ & $9(60,0)$ & \multirow{2}{*}{0,180} \\
\hline$A D$ & $3(25,0)$ & $10(45,4)$ & $6(40,0)$ & \\
\hline Maksimum sistometrik kapasite $(\mathrm{ml})(\mathrm{Ort} \pm \mathrm{SS})$ & $340,00 \pm 123,14$ & $421,59 \pm 140,47$ & $428,00 \pm 129,74$ & 0,189 \\
\hline Kompliyans (ml/cmH $\left.\mathrm{cm}_{2} \mathrm{O}\right)(\mathrm{Ort} \pm \mathrm{SS})$ & $20,85 \pm 19,33$ & $26,02 \pm 20,02$ & $30,42 \pm 23,14$ & 0,341 \\
\hline \multicolumn{5}{|l|}{ Taburculuk mesane boşaltım yöntemi, n (\%) } \\
\hline Daimi kateter & $1(8,3)$ & $2(9,1)$ & - & \multirow{3}{*}{$\mathrm{TE}$} \\
\hline TAK & $10(83,3)$ & $18(81,8)$ & $9(60,0)$ & \\
\hline Spontan & $1(8,3)$ & $2(9,1)$ & $6(40,0)$ & \\
\hline
\end{tabular}

TAK: Temiz aralıklı kateterizasyon, OD: Over-aktif detrüsör, AD: Akontraktil detrüsör, TE: Test edilemedi 
Tablo 5. Nörojenik mesane tipi ile ilişkili faktörler.

\begin{tabular}{|c|c|c|c|}
\hline $\mathrm{n}=49$ & $\begin{array}{l}\text { OD } n=26 \\
\text { Seviyesi }\end{array}$ & $\begin{array}{l}\text { AD } n=23 \\
\text { Ciddiyeti }\end{array}$ & $\mathrm{p}$ \\
\hline Yaş (yll) (Ortt_SS) & $42,61 \pm 15,58$ & $51,95 \pm 18,10$ & 0,058 \\
\hline Cinsiyet, n (\%) Erkek & $15(57,7)$ & $19(82,6)$ & \\
\hline Kadın & $11(42,3)$ & $4(17,4)$ & 0,059 \\
\hline $\begin{array}{l}\text { Maksimum sistometrik } \\
\text { kapasite }(\mathrm{ml})(\mathrm{Ort} \pm \mathrm{SS})\end{array}$ & $345,00 \pm 138,30$ & $469,78 \pm 98,44$ & 0,001 \\
\hline $\begin{array}{l}\text { Kompliyans } \\
\left(\mathrm{ml} / \mathrm{cmH}_{2} \mathrm{O}\right)(\mathrm{Ort} \pm \mathrm{SS})\end{array}$ & $12,88 \pm 6,81$ & $41,05 \pm 21,10$ & 0,000 \\
\hline \multicolumn{4}{|c|}{ Taburculuk mesane boşaltım yöntemi, n (\%) } \\
\hline Daimi kateter & $3(11,5)$ & - & \\
\hline TAK & $19(73,1)$ & $18(78,3)$ & \\
\hline Spontan & $4(15,4)$ & $5(21,7)$ & TE \\
\hline
\end{tabular}

OD: Over-aktif detrüsör, AD: Akontraktil detrüsör, TAK: Temiz aralıklı kateterizasyon, TE: Test edilemedi

arasında pozitif korelasyon olduğu saptanmış olup, daha önceki çalışma sonuçları ile uyumlu bulunmuştur (26). Aynı çalışmada, düşük mesane kompliyansı olan grupta MCC'nin daha düşük olduğu da bildirilmiş̧ir.

Literatürde, OY'li hastalarda mesane boşaltım yöntemini etkileyen faktörleri değerlendiren çok az çalışma mevcuttur $(8,26,27)$. Rapidi ve ark. (8)'nın çalışmasında, OY'li hastalarda yaralanmanın ciddiyeti (komplet/inkomplet) ile mesane boşaltım yöntemi arasında ilişki olmadığı bildirilmiştir. Ku ve ark. (27)’nın araştırmasında da OY'li hastalarda ne lezyon seviyesi ne de ciddiyetinin mesane boşaltma yöntemini etkilemediği ifade edilmiştir. Shin ve ark. (26)'nın çalışmasında, kompliyansın mesane boşaltım yöntemini etkilediği ortaya konulmuştur. Çalışmamızda, taburculuk mesane boşaltım yönteminin MCC, mesane kompliyansı, yaralanma seviyesi ve ciddiyeti ile korelasyon gösterdiği saptanmıştır.

\section{Sonuç}

OY'li hastalarda taburculuk mesane boşaltım yöntemi ile MCC, mesane kompliyansı, yaralanma seviyesi ve ciddiyeti ilişkili bulunarak LS lezyonlu ve inkomplet yaralanmalı hastalarda spontan idrar yapma oranlarının yüksek olduğu tespit edilmiştir. Ancak lezyon seviyesinin ve ciddiyetinin saptanmasının mesane davranışını belirlemede yetersiz olduğu, bu nedenle ürodinamik değerlendirmenin gerekli olacağı sonucuna varılmıştır.

\section{Çıkar Çatışması:}

Yazarlar herhangi bir çıkar çatışması bildirmemişlerdir.

\section{Kaynaklar}

1. $\mathrm{Ku} \mathrm{JH}$. The management of neurogenic bladder quality of life in spinal cord injury. BJU Int 2006;98:739-45.

2. Weld KJ, Dmochowski RR. Association of level of injury and bladder behavior in patients with post-traumatic spinal cord injury. Urology 2000;55:490-4.
3. Çağlar SN, Yılmaz E, Çetinkaya B, Gültekin Ö, Öneş K, Çelik B, et al. The correlation of urodynamic findings with injury levels in patients with spinal cord injury. Turk J Phys Med Rehab 2007;53:50-3.

4. Schurch B, Schmid DM, Kartenty G, Reitz A. Can neurologic examination predict type of dertrusor sphincter-dyssynergia in patients with spinal cord injury? Urology 2005;65:243-6.

5. Weld KJ, Grancy M], Dmochowski RR. Clinical significance of detrussor sphincter diyssynergia type in patients with post-traumatic spinal cord injury. Urology 2000;56:565-8.

6. Wein AJ. Neuromuscular dysfunction of the lower urinary tract and its treatment. In: Walsh PC, Retik AB, Vaughen ED, Campbell MF, editors. Campbell's Urology. Philadelphia: WB Saunders; 1998. p. 953-1006.

7. Akkoç Y. Neurogenic bladder dysfunction "Evaluation, urodynamic studies and classification". Turk J Phys Med Rehab 2005;51(Suppl A):A19-A25.

8. Rapidi CA, Petropoulou K, Galata A, Fragkaki M, Kandylakis E, Venireci M, et al. Neuropathic bladder dysfunction in patients with motor complete and sensory incomplete spinal cord lesion. Spinal Cord 2008;46:673-8.

9. Erol B, Koçak T, Kadıoğlu A, Müslümanoğlu L, Karamehmetoğlu Ş, Akıncı $M$, et al. The relationship between level of injury and bladder behavior in patients with post-traumatic spinal cord injury. Ulus Travma Acil Cerrahi Derg 2009;15:377-82.

10. Maynard FM Jr, Bracken MB, Creasey G, Ditunno JF Jr, Donovan WH, Ducker TB, et al. International standarts for neurological and functional classification of spinal cord injury. American Spinal Cord Injury Association. Spinal Cord 1997;35:266-74.

11. Ersöz $M$, Tunç $H$, Inanır $M$. Myelomeningosel olgularında mesane kapasitesinin incelenmesi ve ürodinamik bulgular. Fiziksel Tıp 2002;5:17-21.

12. Abrams P, Cardozo L, Fall M, Griffiths D, Rosier P, Ulmsten U, et al. The standardisation of terminology of lower urinary tract function: report from the standardisation sub-committee of the International Continence Society. Neurourol Urodyn 2002;21:167-78.

13. Yazıcıoğlu K. Conservative approaches in neurogenic bladder. Turk J Phys Med Rehab 2005;51(1 Suppl A):A26-A32.

14. Chen Z, Sun S, Deng R, Cai D, Yuan X, Du G, et al. The assesment of bladder and urethral function in spinal cord injury patients. J Huazhong Univ Sci Technolog Med Sci 2009;29:609-13.

15. Chua HC, Tow A, Tan ES. The neurogenic bladder in spinal cord injurypattern and management. Ann Acad Med Singapore 1996;25:553-7.

16. Pannek J, Greving I, Tegenthoff M, Nediat S, Bötel U, May B, et al. Urodynamic and rectomanometric findings in patients with spinal cord injury. Neurourol Urodynam 2001;20:95-103.

17. Sacomani CA, Trigo-Rocha FE, Gomes CM, Greve JA, Barros TE, Arap S. Effect of the trauma mechanism on the bladder-sphincteric behavior after spinal cord injury. Spinal Cord 2003;41:12-5.

18. Bradley WE, Conway CJ. Bladder representation in the pontinemesencephalic reticular formation. Exp Neurol 1966;16:237-41.

19. Schmid DM, Curt A, Hauri D, Schurch B. Clinical value of combined electrophysiological and urodynamic recordings to assess sexual disorders in spinal cord injured men. Neurourol Urodyn 2003;22:314-21.

20. Moslavac S, Dzidic I, Kejla Z. Neurogenic detrusor overactivity: Comparison between complete and incomplete spinal cord injury patients. Neurourol Urodyn 2008;27:504-6.

21. Schurch B, Schmid DM, Kaegi K. Value of sensory examination in predicting bladder function in patients with T12-L1 fractures and spinal cord injury. Arch Phys Med Rehabil 2003;84:83-9.

22. Crisp JC, Gren NA, Ashken MH. Urodynamic studies in the District General Hospital. Brit J Urol 1976;48:383-7.

23. Gündüz B, Erhan B. Omurilik yaralanması sonrası gelişen nöropatik mesanenin fizyopatolojisi. Türk Fiz Tıp Rehab Derg 2003;49:3-5.

24. Kılınç Ş, Bayramoğlu M, Peşkircioğlu L, Akman N. Klinik olarak spinal şok dönemi sonlanan hastalarda detrüsör ve ekstarnal üretral sfinkter aktivitesinin incelenmesi. Romatol Tıp Rehab 1999;10:196-8.

25. Kaplan SA, Chancellor MB, Blaivas JG. Bladder and sphincter behavior in patients with spinal cord lesions. J Urol 1991;146:113-7.

26. Shin JC, Park CI, Kim HJ, Lee IY. Significance of low compliance bladder in cauda equina injury. Spinal Cord 2002;40:650-5.

27. Ku JH, Choi WJ, Lee KY, Jung TY, Lee JK, Park WH, et al. Complications of the upper urinary tract in patients with spinal cord injury: a long-term follow-up study. Urol Res 2005;33:435-9. 